\title{
BEARING CAPACITY OF THE WORKING PLATFORM WITH KINEMATIC METHOD
}

\author{
KATARZYNA BIAŁEK, LECH BAŁACHOWSKI \\ Gdańsk University of Technology, Faculty of Civil and Environmental Engineering, Gdańsk, Poland, \\ e-mail: abal@pg.gda.pl
}

\begin{abstract}
Bearing capacity of the working platform for heavy tracks was analysed using Distinct Layout Optimization (DLO) method. The platform layer constructed from cohesionless soils is resting on weak cohesive subgrade. Different thickness of the platform, its effective angle of internal friction and undrained shear strength of the soft soil were taken into consideration. Kinematic method permits different failure mechanisms to be analyzed. Margin of safety for a given load and subsoil conditions was determined using two approaches: increasing the load or decreasing the shear strength up to failure. The results were compared with solution proposed in BRE recommendations.
\end{abstract}

Key words: soft soil, undrained shear strength, limit state, failure mechanism

\section{INTRODUCTION}

The safe traffic of heavy trucks or rigs and the proper execution of soil improvement or piling works need a special platform to be constructed over the soft subsoil. Such a platform can be formed from either compacted cohesionless material or from soil material improved with hydraulic binders, cement or lime. In this paper, the working platform built from cohesionless soil overlying cohesive subgrade is analyzed. The design of working platforms can be considered as a bearing capacity problem of layered soil with softer one underlying the bearing strata. The bearing capacity of such two layer subsoil is a general problem to be considered in shallow foundations (Das [1]), in the case of sand cushion (Sękowski [2]), when laboratory tests on reduced models or in-situ tests in natural scale were used or in off-shore engineering, where the behaviour of spud-can foundations was physically modeled in centrifuge tests (Lee et al. [3]). The latter approach permits advanced parametric studies concerning the foundation geometry and the subsoil characteristics to be held. Semi-analytical solutions exists based on the experimental test results (Meyerhof [4], Hanna and Meyerhof [5]) and analytical studies using kinematical methods (Florkiewicz [6], Michałowski and Shi [7]) and FEM and DEM analysis (Burd and Frydman [8]). The punching shear failure within the platform material is assumed by Meyerhof [4] and Hanna and Meyerhof [5], while the influence of load spread angle in the platform was considered by Burd and Frydman [8] as a function of angle of internal friction of the platform material and the undrained shear strength of the weak subgrade. The analysis included also the effect of overconsolidation of cohesive layer.

The limit analysis in soil and rock mechanics was accomplished by Izbicki and Mróz [9]. The generalized kinematical method was used for the optimization of failure patterns in slope stability analysis in plane strain conditions assuming different number of rigid blocks, Bagińska and Izbicki [10]. The application of this method for the slope stability analyses in layered frictional soil was studied by Bagińska and Izbicki [10]. Florkiewicz [6] used upper-bound theorem to analyze the general case of multilayered soil with inclined and horizontal strata. The deformation patterns and hodograph were presented for cohesive or cohesionless layers and cohesionless soil overlying cohesive layer. The effect of different values of angle of internal friction in various layers on the hodograph and velocities jumps between rigid blocks was analyzed. The results of numerical analysis concerning the bearing capacity of strip foundation were compared to the model test results. Michałowski and Shi [7] considered the upper-bound solution of bearing capacity of strip foundation on granular soil overlaying cohesive layer. The impact of soft layer 
on the kinematically admissible solution was studied and the critical depth of soft layer was established. Design charts in dimensionless form for bearing capacity of sand-clay subsoil were given.

The solutions presented above are included in BRE [12] recommendations for the design, construction repair and maintenance of working platform. Relatively shallow thickness of the platform is here considered and the calculation is based on punching failure mechanism. The bearing resistance is considered to be the sum of the shear required to punch through a vertical plane in the granular platform and the bearing capacity of the weak subgrade. This simplified approach gives conservative results of bearing capacity. The calculation method is not appropriate for a very soft subgrade with undrained shear strength lower than $20 \mathrm{kPa}$. The special measures will be then needed to construct a working platform and more sophisticated design should be applied. The calculation method is not appropriate for a firm subgrade with $c_{u}$ larger than $80 \mathrm{kPa}$, as in many cases the bearing capacity of the subgrade itself will be sufficient to support the plant. As the method does not consider the general failure mechanism within the platform material it can be used only for the relative platform thickness not exceeding 1.5. The load parameters including different phase of the machine working and the corresponding foundation shape can be calculated for a given machine.

The behaviour of such system was also studied in laboratory model tests at GUT and with the use of FEM modelling, Białek [13]. The bearing capacity, the different failure modes and the load spread angle in the working platform subjected to strip loading was determined for the reduced strip model in plane strain conditions.

\section{SOIL AND GEOMETRY CONDITIONS}

The general scheme of the problem is given in Fig. 1. The thickness $h$ of the upper cohesionless layer is variable, while the thickness of the weak subgrade is fixed as $5 \mathrm{~m}$. It is assumed that the track, $0.7 \mathrm{~m}$ long, transmits a uniform load of $77 \mathrm{kPa}$ to the subsoil. The platform made up from medium sand has the effective angle of internal friction $\phi^{\prime}$ equal $32^{\circ}$. The soft layer is characterized by the undrained shear strength $c_{u}$ in the range from 10 to $50 \mathrm{kPa}$ assumed to be constant in the soil profile.

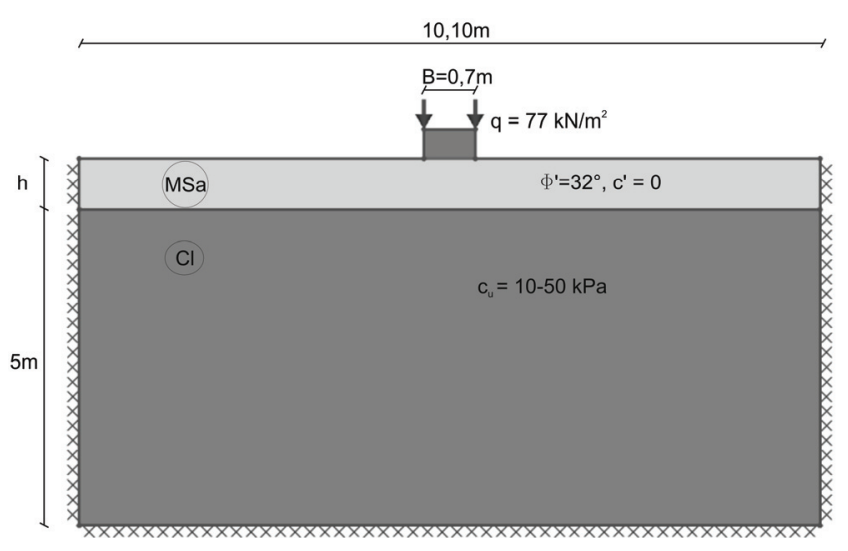

Fig. 1. General scheme of the working platform

\section{DISTINCT LAYOUT OPTIMIZATION (DLO) METHOD}

The kinematically admissible solution of the bearing capacity problem is determined in this paper using academic version of LimitState GEO software. LimitState GEO uses the Discontinuity Layout Optimization (DLO) procedure, developed at the University of Sheffield by Smith and Gilbert [15]. The procedure finds the true critical slip-line failure mechanism according to the following steps: (a) starting problem, (b) discretisation of soil using nodes, (c) interconnection of nodes with potential discontinuities, (d) identification of critical subset of potential discontinuities using optimization (giving the critical failure mechanism). The Mohr-Coulomb model is used for soils. In this paper, the bearing capacity of such bi-layered system is analyzed including different thickness of the platform and variable undrained shear strength of the soft subgrade. The optimization procedure is implemented to identify critical slip surface. The patterns of rigid sliding blocks in plane strain conditions together with interblock forces can be obtained. The calculated bearing capacity comes from kinematically admissible solution and according to plasticity theorem forms the upper bound of the limit state. These results are compared with semi-analytical solution included in BRE [12] recommendations.

DLO is the principal method used in this paper to determine the bearing capacity of working platform. Two different approaches are considered. When "Factor on load" approach is used, the load at which failure occurs is determined, so it is possible to calculate the margin of safety concerning the applied load. If "Factor on strength" approach is chosen the soil strength parameters, i.e., $\operatorname{tg}\left(\phi^{\prime}\right)$ and $c^{\prime}$ or $c_{u}$, are 
divided by a certain factor to induce failure. In this way one can obtain the margin of safety concerning effective or total strength parameters of the subsoil.

The LimitState GEO permits to apply the partial factors concerning both actions and strength parameters in order to meet the requirements of calculations according to Eurocode 7. Two selection methods of partial factors for subgrade and load parameters were used. In the first approach, all partial factors were equal to 1 (unity case). The second method consists on establishing a set of partial factors for the subgrade material due to EC-7 using Design Approach 1b with factoring materials only. The partial factor for load $\gamma_{F}$ is equal to 1. Partial factors for soil strength parameters were assumed as follows:

$$
\begin{aligned}
& \gamma_{\phi^{\prime}}=1.25, \\
& \gamma_{c^{\prime}}=1.25, \\
& \gamma_{c_{u}}=1.4 .
\end{aligned}
$$

It was assumed that the platform behaves as a drained material and the weak subsoil as an undrained one. The Mohr-Coulomb soil model was chosen. The contact area between caterpillar and working platform is characterised by the boundary element with thickness equal to zero and the interface friction angle assumed as a half of the friction angle of the platform material.

\section{CALCULATION RESULTS}

The failure mechanisms with "Factor on load" approach, where all partial factors are equal to 1 (unity case), were analyzed for the different relative thickness of the platform and the undrained shear strength of the cohesive subgrade. The analyses were made for the effective angle of the internal friction of the platform material $\phi^{\prime}=32^{\circ}$.

The failure patterns obtained for the relative thickness of the platform $(h / B)=0.5$ and for the undrained shear strength $c_{u}$ equal 10 and $50 \mathrm{kPa}$ are given in Fig. 2 and Fig. 3. Factor on load calculated for partial factors equal 1 is also presented in these pictures. The punching failure mechanism for $(h / B)=0.5$ is observed irrespective of the undrained shear strength. In a very soft subsoil $\left(c_{u}=10 \mathrm{kPa}\right)$ additional local shear patterns are developed. The failure mechanism, however, does not penetrate into firm subgrade $\left(c_{u}=50 \mathrm{kPa}\right)$ and the slippage lines occur in the contact between two layers.

The failure mechanism for the relative thickness of the platform $(h / B)=2$ and the undrained shear strength $c_{u}$ equal $10 \mathrm{kPa}$ is shown in Fig. 4. As the thickness of the stronger layer increases the punching failure mechanisms is no more valid and the general shear failure in the platform material occurs.

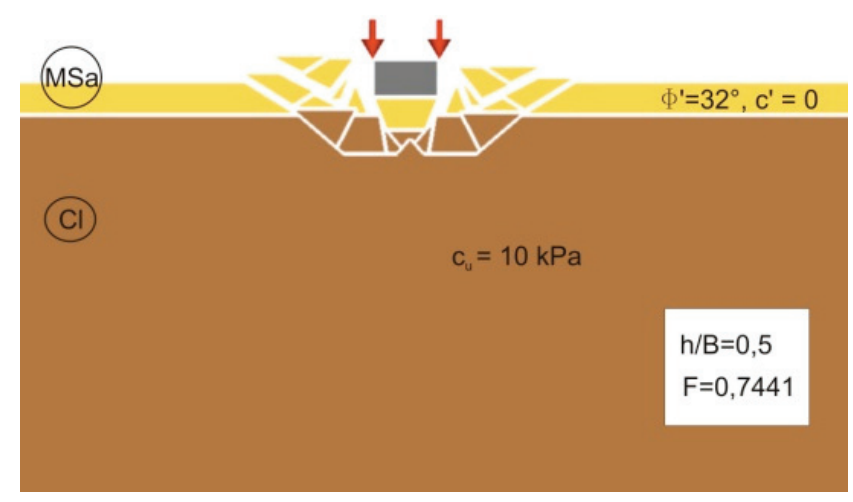

Fig. 2. Failure mechanisms for $(h / B)=0.5$ and the undrained shear strength $10 \mathrm{kPa}$

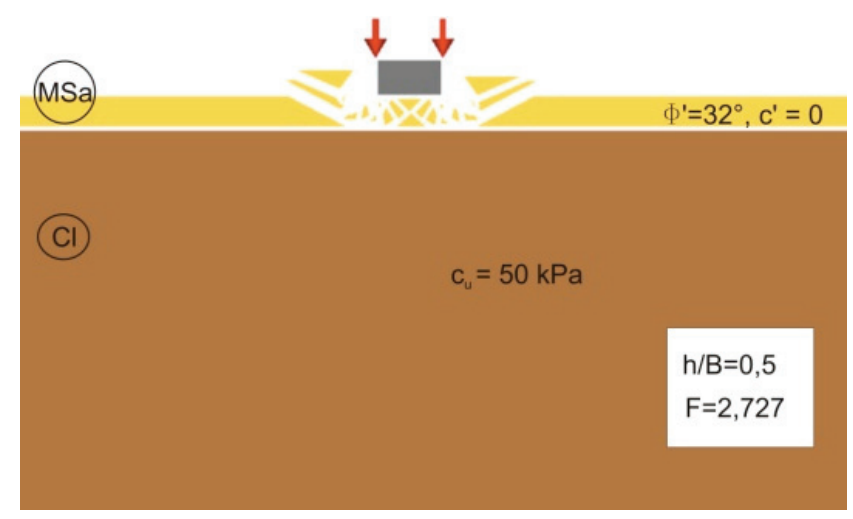

Fig. 3. Failure mechanisms for $(h / B)=0.5$ and the undrained shear strength $50 \mathrm{kPa}$

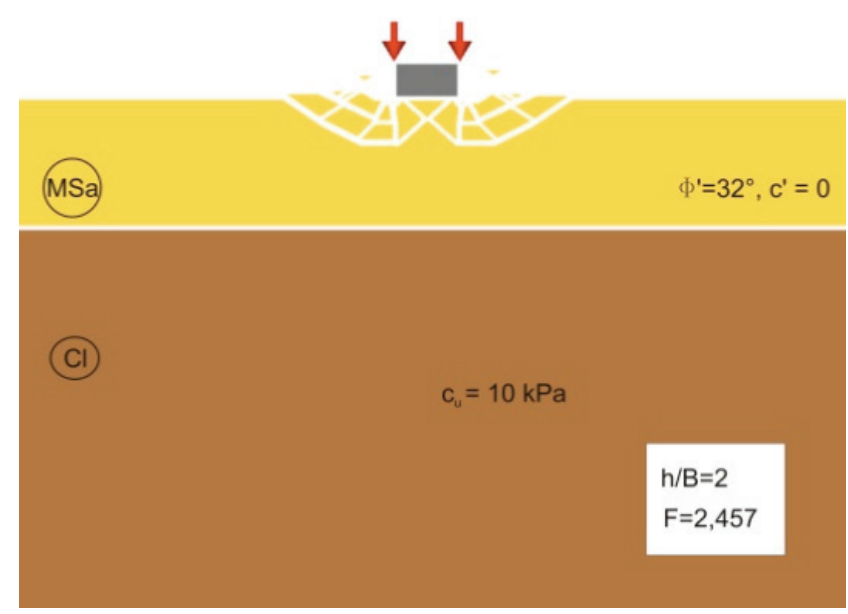

Fig. 4. Failure mechanisms for $(h / B)=2$ and the undrained shear strength $10 \mathrm{kPa}$

The calculation results according to DLO method with "Factor on load" approach where all partial factors are equal to 1 (unity case) are given in Fig. 5 as a func- 
tion of the relative thickness of the platform $(h / B)$ and the undrained shear strength of the soft subgrade. Factor on load increases with the undrained shear strength and the relative thickness of the platform and is reaching the stable value for $(h / B)$ approaching 2. This maximum value of factor on load is common for the undrained shear strength in the range from 20 to $50 \mathrm{kPa}$, where the bearing capacity of the bi-layered subsoil is governed by the shear strength of the platform itself and not by the underlying cohesive strata. In the case of large thickness of the platform the factor on load for $c_{u}=10 \mathrm{kPa}$ is substantially lower. This can be explained by the different failure mechanism when a very soft layer exists below the stronger one.

If typical value of the safety coefficient for bearing capacity of shallow foundation is used, the foundation stability is satisfied for the factor on load value above 2 . This happens (see Fig. 5) when the relative thickness of the platform $(h / B)$ exceeds:

$$
\begin{aligned}
& -1.7 \text { for } c_{u}=10 \mathrm{kPa}, \\
& -1.5 \text { for } c_{u}=20 \mathrm{kPa}, \\
& -0.4 \text { for } c_{u}=30 \mathrm{kPa},
\end{aligned}
$$

and in all the cases if $c_{u}=50 \mathrm{kPa}$.

The results for the calculation according to EC-7 are shown in Fig. 6, where similar tendencies are observed. The different shape of the curves, as compared to Fig. 5, results from different partial factors applied for the platform material and the soft layer. Finally, all curves converge to the factor on load close to 1.6 for $(h / D)$ larger than 2, regardless of undrained shear strength. The foundation stability is assured here if the factor on load exceeds 1 . It appears when relative thickness of the platform $(h / B)$ exceeds:

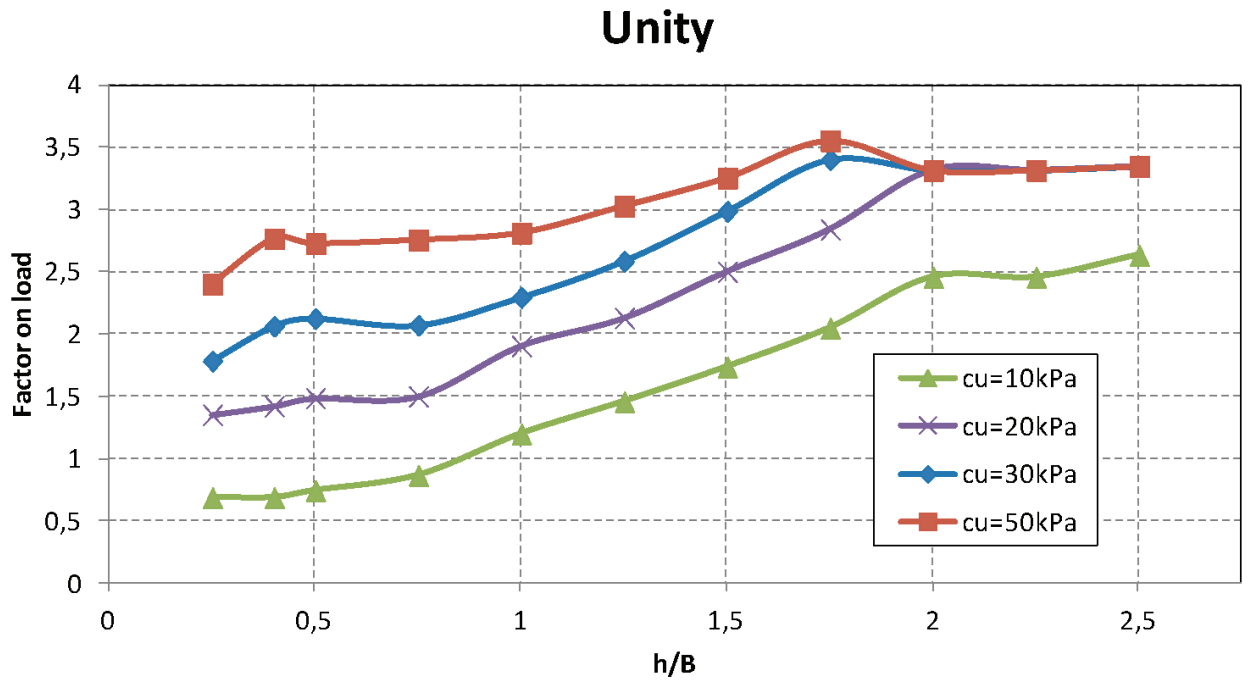

Fig. 5. Factor on load vs. relative thickness of the platform for different $c_{u}$ (unity case)

EC7

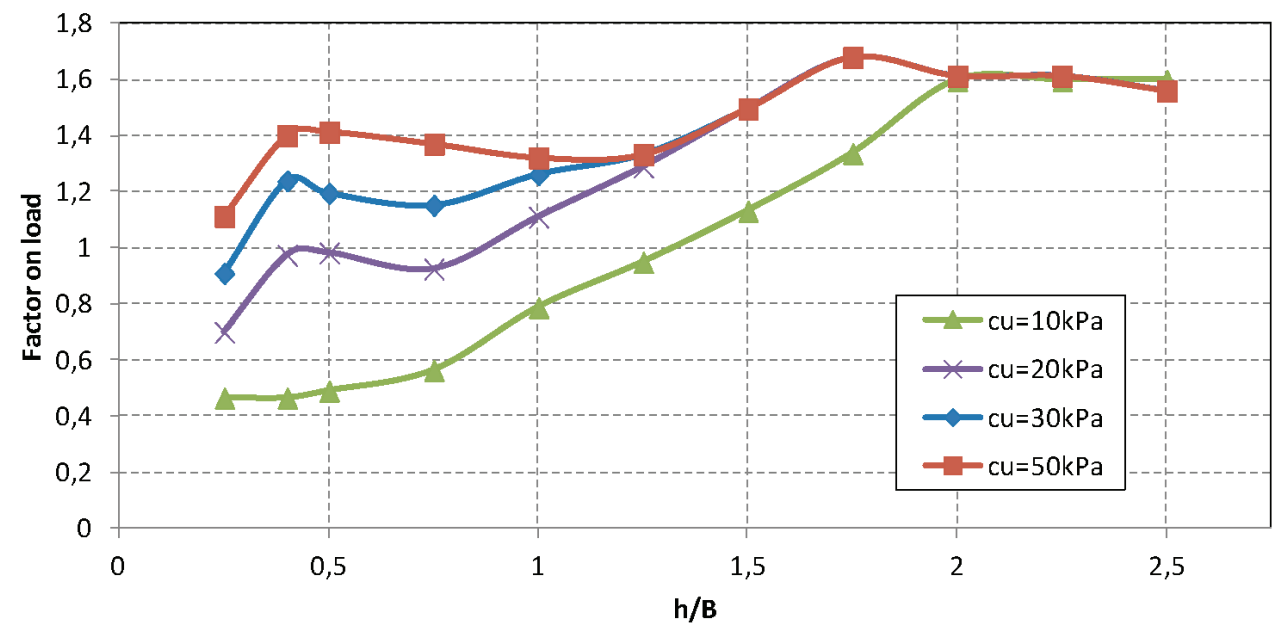

Fig. 6. Factor on load vs. relative thickness of the platform for different $c_{u}$ (EC-7 partial factors) 
-1.3 for $c_{u}=10 \mathrm{kPa}$,

-0.9 for $c_{u}=20 \mathrm{kPa}$,

-0.3 for $c_{u}=30 \mathrm{kPa}$,

and in all the cases for $c_{u}=50 \mathrm{kPa}$. One can notice that the minimal relative thickness of the platform obtained with all partial factors equal 1 is systematically greater than that calculated for EC-7 Design Approach 1b. Thus the solution with partial coefficients assumed as 1 gives more conservative results than Design Approach 1b.

The results according to "Factor on strength" approach with partial factors for soil parameters equal 1 are given in Fig. 7 as a function of the relative thickness of the platform and undrained shear strength of the weak subgrade. The margin of safety thus obtained cannot be compared directly with that calculated with "Factor on load" approach. However, one can notice that the factor on strength for very soft subsoil $\left(c_{u}=\right.$ $10 \mathrm{kPa}$ ) is significantly lower. It is even smaller than 1 for the relative thickness of the platform layer up to 0.8 . For $(h / B)$ exceeding 1.5 all results converge to the factor on strength close to 1.4 , regardless of the undrained shear strength. It means that the bearing capacity of the working platform is no more dependent on the soft subgrade as the failure mechanism occurs solely within the upper layer as shown in Fig. 4.

The bearing capacity of the two-layer system can also be estimated using semi-analytical methods. Ac-

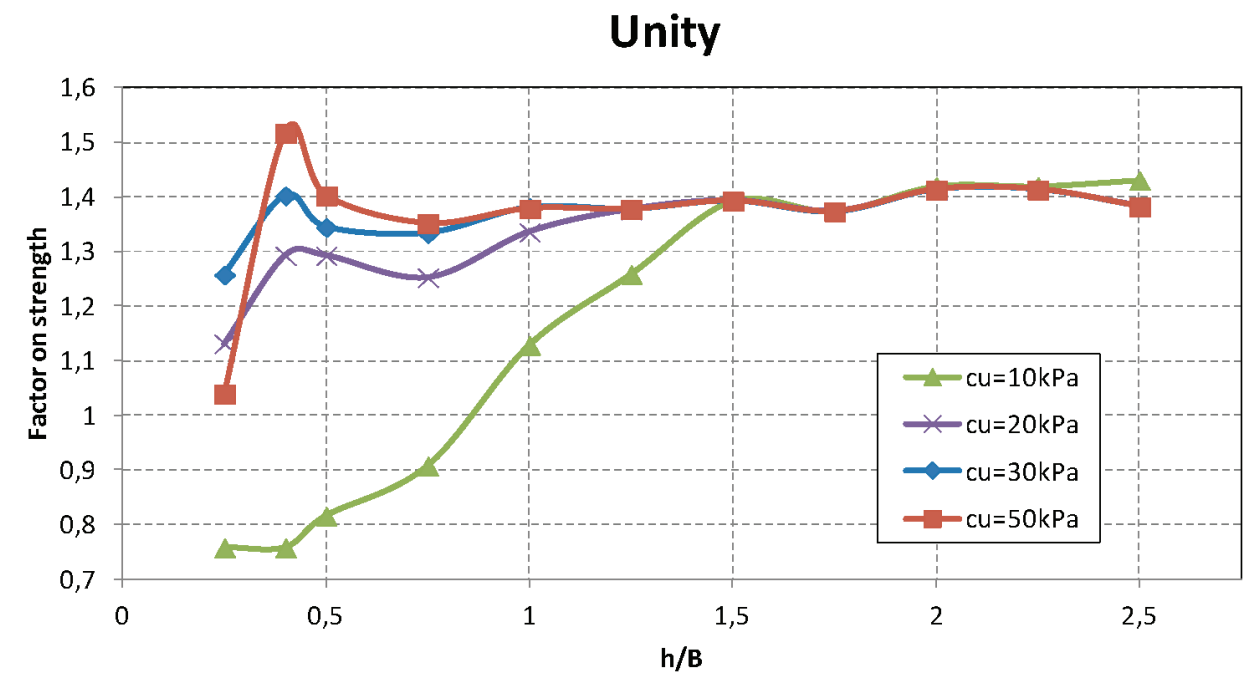

Fig. 7. Factor on strength vs. relative thickness of the platform for different $c_{u}$ (unity case)

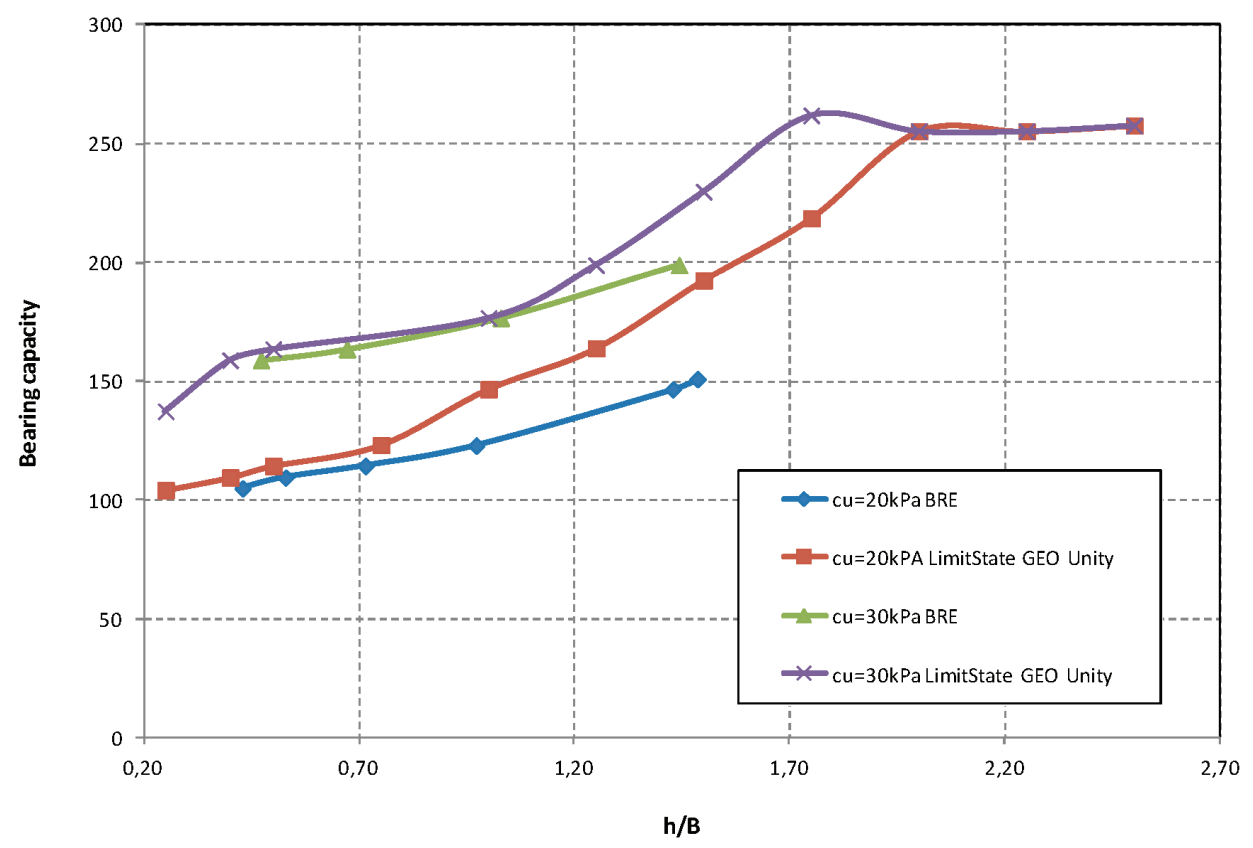

Fig. 8. Bearing capacity determined with LimitState GEO and BRE recommendation 
cording to BRE 470 recommendation one can calculate the necessary platform thickness for a given load, foundation shape and strength parameters of the platform $\left(\phi^{\prime}\right)$ and the soft subgrade $\left(c_{u}\right)$. The analysis based on punching failure however represents a major simplification of the actual field situation and is valid for $(h / B)$ not greater than 1.5. The use of BRE recommendations is also restrained to the weak subsoil with $c_{u}$ above $20 \mathrm{kPa}$. In this paper, the bearing capacity of the working platform was determined for the assumed thickness of the upper layer. The calculations were performed for strip foundation for two values of undrained shear strength $(20 \mathrm{kPa}$ and $30 \mathrm{kPa})$. These results are compared (Fig. 8) with LimitState GEO calculation using the factor on load approach and partial factors equal 1 . The bearing capacity determined with LimitState GEO as a kinematically admissible solution is generally slightly higher than that calculated according to BRE.

\section{CONCLUSIONS}

The bearing capacity of sandy layer overlying weak cohesive subgrade was analyzed using Distinct Layout Optimization method, where kinematically admissible solution for strip foundation is sought for. Two approaches considering the evaluation of safety margin for a given soil geometry and loading were taken into account. Factor on load approach provides the safety margin and permits the bearing capacity of the working platform to be determined directly. Factor on strength approach is less straightforward as it gives the safety margin on the shear strength of the subsoil. The analysis performed for different relative thickness of the platform and variable undrained shear strength of the weak subgrade permit to associate the bearing capacity of strip foundation with kinematical mechanism of failure. As the thickness of the platform increases the failure mechanisms change progressively from punching failure in the platform material and local shear in the soft subgrade to the generalized shear failure within the platform. In this case the bearing capacity of the foundation is related to the shear strength of the upper sandy layer. The factors on load, except very soft subgrade with $c_{u}=10 \mathrm{kPa}$, converge to the same maximum value for $(h / B)$ higher than 2 . The factor on strength approaches the same maximum value for $(h / B)$ exceeding 1.5. The effect of different partial factoring including unity case and Design Approach 1b in EC-7 was also studied. For a given strip loading the latter gives smaller thickness of the platform than unity case.
Kinematic solution according to DLO provides higher values of bearing capacity than those calculated using BRE recommendations. The application of BRE recommendations is limited to the clay subgrade with the undrained shear strength between $20 \mathrm{kPa}$ and $80 \mathrm{kPa}$. The analysis concerning a very soft clay with $c_{u}$ in the range from $10 \mathrm{kPa}$ to $20 \mathrm{kPa}$ is the objective of another paper based on LimitState GEO analysis. Further studies will also concern the effect of linear distribution with depth of undrained shear strength in the weak subgrade.

\section{REFERENCES}

[1] DAS B.M., Shallow foundations, Bearing capacity and settlements, CRC Press, 2009.

[2] SĘKOWSKI J., Experimental verification of soft subsoil loadbearing cushion, Studia Geotechnica et Mechanica, 2008, Vol. XXX, No. 3-4, 45-69.

[3] LEE K.K., CASSIDY M.J., RANDOLPH M.F., Bearing capacity on sand overlying clay soils: experimental and finite element investigation of potential punch-through failure, Géotechnique, 2013, 63, No. 15, 1271-1284.

[4] MeYerhoF G.G., Ultimate bearing capacity of footing on sand layer overlying clay, Canadian Geotechnical Journal, 1874, 11(2), 223-229.

[5] Hanna A.M., Meyerhof G.G., Design charts for ultimate bearing capacity for sands overlying clays, Canadian Geotechnical Journal, 1980, 17(2), 300-303.

[6] FloRKIEWICZ A., Upper bound to bearing capacity of layered soils, Canadian Geotechnical Journal, 1989, 28(4), 730-736.

[7] MichalOWSKI R.L., SHI L., Bearing capacity of footings over two-layer foundation soils, Journal of Geotechnical Engineering, ASCE, 1995, 121(5), 421-428.

[8] BuRd H.J., Frydman S., Bearing capacity of plane-strain footings on layered soils, Canadian Geotechnical Journal, 1997, 34, 241-253.

[9] IzBICKI R.J., Mróz Z., Methods of limit analysis in soil and rock mechanics, Polish Science Publishers, Warszawa, Poland 1976, (in Polish).

[10] BAGIŃSKA I., IZBICKI R.J., Optymalizacja geometrii bryty odłamu w uogólnionej metodzie elementów kinematycznych, Górnictwo i Geoinżynieria, 2010, Vol. 34, Z. 2, 53-60.

[11] BAGIŃSKA I., IZBICKI R.J., Niejednorodność ośrodka gruntowego $w$ kinematycznej analizie stateczności zboczy, Górnictwo i Geoinżynieria, 2008, Vol. 32, Z. 2, 27-33.

[12] BRE Report 470, Working platforms for tracked plant: good practice guide to the design, installation, maintenance and repair of ground supported working platforms, Watford, 2004.

[13] BIAŁEK K., Analysis of the punching failure mechanism in working platforms, Proceedings of the 5th International Young Geotechnical Engineers' Conference, ed. YU-Jun Cui Amsterdam, 2013, IOS Press BV, 399-402.

[14] LimitState Ltd, LimitState:GEO Manual VERSION 3.2.a, 2014.

[15] SMith C.C., GilBert M., Application of discontinuity layout optimization to plane plasticity problems, Proceedings of the Royal Society A: Mathematical, Physical and Engineering Sciences, 2007, 463 (2086), October, 2461-2484. 